\title{
Exergy and Exergoenvironmental Analysis of a CCHP System Based on a Parallel Flow Double-Effect Absorption Chiller
}

\author{
Ali Mousafarash \\ Mechanical Engineering Department, Shahid Rajaee Teacher Training University (SRTTU), Tehran 16788 15811, Iran \\ Correspondence should be addressed to Ali Mousafarash; alimoosafarash@gmail.com
}

Received 3 November 2015; Revised 27 March 2016; Accepted 14 April 2016

Academic Editor: Halil S. Hamut

Copyright (C) 2016 Ali Mousafarash. This is an open access article distributed under the Creative Commons Attribution License, which permits unrestricted use, distribution, and reproduction in any medium, provided the original work is properly cited.

\begin{abstract}
A combined cooling, heating, and power (CCHP) system which produces electricity, heating, and cooling is modeled and analyzed. This system is comprised of a gas turbine, a heat recovery steam generator, and a double-effect absorption chiller. Exergy analysis is conducted to address the magnitude and the location of irreversibilities. In order to enhance understanding, a comprehensive parametric study is performed to see the effect of some major design parameters on the system performance. These design parameters are compressor pressure ratio, gas turbine inlet temperature, gas turbine isentropic efficiency, compressor isentropic efficiency, and temperature of absorption chiller generator inlet. The results show that exergy efficiency of the CCHP system is higher than the power generation system and the cogeneration system. In addition, the results indicate that when waste heat is utilized in the heat recovery steam generator, the greenhouse gasses are reduced when the fixed power output is generated. According to the parametric study results, an increase in compressor pressure ratio shows that the network output first increases and then decreases. Furthermore, an increase in gas turbine inlet temperature increases the system exergy efficiency, decreasing the total exergy destruction rate consequently.
\end{abstract}

\section{Introduction}

Fossil fuels release harmful gases to the atmosphere; in addition, they have limited resources that will be exhausted in the early future. Such a fact makes the world face a serious crisis in the 21st century. An increase in earth temperature and seriousness of greenhouse gases may burden extra costs on industries and the economy of those countries with high per capita consumption. Due to fossil fuel depletion, increasing fuel prices, and energy demand the use of high efficiencies power plants is very important. In traditional power generation systems a large amount of heat is lost by exhaust gases. Consequently using of waste heat increases power plant's efficiency. The combined cooling, heating, and power (CCHP) is a system that can produce power, heating, and cooling from a common energy source such as natural gas, oil, or sun. In a CCHP system, waste heat drives heating and cooling devices. The waste heat can be used for space heating, domestic hot water production, or production of steam. The waste heat can be used for cooling by driving a refrigeration system like an absorption chiller. The overall energy efficiency of a trigeneration plant can attain $80 \%$ [1]. Through the absorption chiller and heat recovery steam generator in these systems, the extra heat releasing from the gas turbine can provide the needed cryogenic and thermal energies of a given site and supply the electricity without any separate consumption of fuel.

In recent years, economy is not the only matter; built environment is important too. Numerous studies have been carried out to reduce the greenhouse gas emissions and there have been several efforts worldwide to come up with plans and strategies for global warming mitigation. Nowadays, environmental impact of a plant is a design consideration beside the plants' economy. Furthermore, due to energy resources shortages, systems are designed to utilize the energy sources as efficient as possible. Economy, environment, and sustainability of energy resources are the basic criteria for any energy systems. By the advent of the exergy definition, exergy efficiency has become popular since it has a close relation with sustainability. Furthermore, because exergy evaluates the exact value of the extractable work from a stream or resource, it is more suitable for economic evaluation and 
analysis. Hence, the exergy-economic and environmental assessment and modeling approach is an acceptable method for analyzing and designing the energy systems.

Exergy efficiency stands for energy sources management but linked with the economy of the plant and has a direct relationship with environmental emission. Since then it is always subjected to optimization. Other objectives are cost of the plant and emission. Nowadays, carbon taxes and emission cost are evaluated and implemented in plant cost considerations. Other emissions like $\mathrm{NO}_{x}, \mathrm{SO}_{x}$, and $\mathrm{CO}$ which are classified as toxic or hazard gases have their own costs and taxes as well. To evaluate the exact plant cost these issues must add to the total cost of the plant.

Havelský [2] analyzed the problem of energy efficiency evaluation of cogeneration systems for combined heating, cooling, and power production and presented equations for energy efficiency and primary energy savings. Athanasovici et al. [3] offered a unified comparison method for the thermodynamic efficiency of combined heat and power plants. A comparison between separate and combined energy production processes has been studied by using this analysis method. Minciuc et al. [4] proposed a method for the analysis of triple generation systems and established some limiting thermodynamic boundaries for optimum performance of triple generation systems combined with absorption chiller.

Sahoo [5] performed economic energy for a combined power and heat system. Huicochea et al. [6] analyzed theoretically the thermodynamic performance of a trigeneration system formed by a microturbine and a double-effect water/LiBr absorption chiller and evaluated that at different operating conditions. Ahmadi et al. [7] carried out energy and exergy analyses, environmental impact assessments, and related parametric studies for a trigeneration system. Their results show that trigeneration exhibits higher exergy efficiencies and lower environmental impacts compared to typical combined heat and power systems or gas turbine cycles.

Al-Sulaiman et al. [8] indicated that using the trigeneration plant compared with the power cycle eventuated efficiency gain of more than $22 \%$. They also demonstrate the maximum efficiency is $74 \%$ for the trigeneration system, $71 \%$ for CHP system, and $46 \%$ for net electricity generation. Amrollahi et al. [9] performed thermodynamic analysis of postcombustion $\mathrm{CO}_{2}$ capture in a natural gas-fired power plant. Rezaie and Rosen [10] have reviewed district energy systems and possible future developments. They discussed various assortments, definitions, and applications of district cooling and heating and described elements of a district energy system.

In this research study, exergy and environmental impact assessment are performed for a trigeneration system based on a parallel flow double-effect absorption chiller modeled by thermodynamic equations. The parametric evaluations of changes on selected design parameters (compressor pressure ratio, gas turbine inlet temperature, gas turbine isentropic efficiency, compressor isentropic efficiency, and temperature of absorption chiller generator inlet) on exergy and energy efficiencies were evaluated.

\section{Energy Analysis}

In this part, the CCHP cycle is modeled using EES software, by thermodynamic equations. To determine energy of different lines, it is required to identify thermodynamic parameters of the cycle through modeling its components. Modeling of each component is performed in terms of the first law and mass-energy balance law. Next, exergy of various points in the cycle, shown in Figure 1, is calculated and exergy efficiency and destruction are computed by writing the exergy balance for every component of the cycle.

2.1. Gas Turbine Cycle. Gas turbine cycle was modeled based on first law of thermodynamics. As shown in Figure 1, the air enters the compressor at ambient conditions (point 1); hot air then enters a combustion chamber where fuel is injected to increase its temperature at point 3. Next, the flue gas generated from combustion in the combustion chamber is extracted (point 3) and the power is produced by passing this gas from gas turbine (point 4). Gas turbine cycle wastes typically occur in three main components including compressor, combustion chamber, and gas turbine. To calculate irreversibility computations for each component, it is required to consider each of them as a control volume. Energy balance and the governing equations of this cycle components are as follows.

Air compressor:

$$
\begin{aligned}
T_{2} & =T_{1}\left(1+\frac{1}{\eta_{c}}\left(r_{c}^{\left(\gamma_{a}-1\right) / \gamma_{a}}-1\right)\right), \\
\dot{W}_{c} & =\dot{m}_{a} C_{p a}\left(T_{2}-T_{1}\right),
\end{aligned}
$$

where $\dot{m}_{a}$ is air mass flow rate, $\eta_{c}$ is air compressor isentropic efficiency, $\gamma_{a}$ is specific heat ratio, $r_{c}$ is compressor pressure ratio, and $C_{p a}$ is considered a function of temperature as follows [11]:

$$
\begin{aligned}
C_{p a}(T)= & 1.048-\left(\frac{1.83 T}{10^{4}}\right)+\left(\frac{9.45 T^{2}}{10^{7}}\right) \\
& -\left(\frac{5.49 T^{3}}{10^{10}}\right)+\left(\frac{7.92 T^{4}}{10^{14}}\right) .
\end{aligned}
$$

Combustion chamber:

$$
\begin{aligned}
\dot{m}_{a} h_{2}+\dot{m}_{f} \mathrm{LHV} & =\dot{m}_{g} h_{3}+\left(1-\eta_{\mathrm{CC}}\right) \dot{m}_{f} \mathrm{LHV}, \\
\frac{P_{3}}{P_{2}} & =\left(1-\Delta P_{\mathrm{CC}}\right), \\
\dot{m}_{g} & =\dot{m}_{a}+\dot{m}_{f} .
\end{aligned}
$$

Gas turbine:

$$
\begin{aligned}
T_{4} & =T_{3}\left(1-\eta_{\mathrm{GT}}\left(1-r_{\mathrm{GT}}^{\left(1-\gamma_{g}\right) / \gamma_{g}}\right)\right), \\
\dot{W}_{\mathrm{GT}} & =\dot{m}_{g} C_{p g}\left(T_{3}-T_{4}\right), \\
\dot{W}_{\text {net }} & =\dot{W}_{\mathrm{GT}}-\dot{W}_{c},
\end{aligned}
$$


where $\dot{m}_{f}$ is fuel mass flow rate, $\dot{m}_{a}$ is air mass flow rate, $\dot{m}_{g}$ is combustion gases mass flow rate, LHV is the fuel lower heating value, $\eta_{\mathrm{CC}}$ is combustion chamber efficiency, $\gamma_{g}$ is combustion gases specific heat ratio, $r_{\mathrm{GT}}$ is gas turbine pressure ratio, and $C_{p g}$ is considered a function of temperature as follows [11]:

$$
\begin{aligned}
C_{p g}(T)= & 0.991+\left(\frac{6.997 T}{10^{5}}\right)+\left(\frac{2.712 T^{2}}{10^{7}}\right) \\
& -\left(\frac{1.2244 T^{3}}{10^{10}}\right) .
\end{aligned}
$$

2.2. Heat Recovery Steam Generator (HRSG). The considered single pressure HRSG consists of an economizer and an evaporator to produce steam. The supply water enters first to the economizer and its temperature rises up to saturation temperature. Then, it enters to the evaporator and vapor quality approaches 1 at a constant temperature and pressure. Some of the vapor enters to absorption chiller and the remaining is used in heat applications. The energy balance for the assumed HRSG is as follows.

Evaporator:

$$
\dot{m}_{g} C_{p g}\left(T_{a}-T_{b}\right)=\dot{m}_{36}\left(h_{37}-h_{36}\right) .
$$

Economizer:

$$
\begin{aligned}
\dot{m}_{g} C_{p g}\left(T_{4}-T_{a}\right) & =\dot{m}_{37}\left(h_{38}-h_{37}\right), \\
\mathrm{PP} & =T_{a}-T_{38}, \\
\mathrm{AP} & =T_{38}-T_{37},
\end{aligned}
$$

where $C_{p g}$ is combustion gases specific heat at constant pressure and the pinch point (PP) is defined as the difference between the temperature of the gas at the entrance of the evaporator $\left(T_{a}\right)$ and the saturation temperature $\left(T_{38}\right)$ and the approach point (AP) is the temperature differences between the water leaving the economizer $\left(T_{37}\right)$ and the saturation temperature $\left(T_{38}\right)$.

2.3. Double-Effect Absorption Chiller. In the considered CCHP system in this study, a Li-Br parallel flow double-effect absorption chiller is modeled. It must be noted that, during modeling of this chiller, the hot water output flowing from high-temperature generator (point 6) was used for heating the convection flow of the water and lithium bromide solution to increase the chiller performance. Doing so, coefficient performance of the proposed model increases to about 0.1 . Each component of the chiller is assumed as a control volume and their mass-energy balance and thermodynamic equations are expressed as follows [7]:

$$
\begin{aligned}
\sum \dot{m}_{\mathrm{in}} & =\sum \dot{m}_{\mathrm{out}}, \\
\sum(\dot{m} x)_{\text {in }} & =\sum(\dot{m} x)_{\mathrm{out}}, \\
\dot{Q}-\dot{W} & =\sum(\dot{m} h)_{\mathrm{out}}-\sum(\dot{m} h)_{\mathrm{in}},
\end{aligned}
$$

where $\dot{m}$ is working fluid mass flow rate and $x$ is mass concentration of $\mathrm{Li}-\mathrm{Br}$ in the solution.
2.4. Assumptions. Several assumptions have been used to simplify the model:

(i) All the processes are done at steady state.

(ii) Natural gas is the fuel used in the combustion chamber.

(iii) The dead state is $P_{0}=1.01$ bar and $T_{0}=293.15 \mathrm{~K}$.

(iv) Air and combustion products are assumed to be idealgas mixtures.

\section{Exergy Analysis}

Exergy in a system of ideal machines is defined as the maximum theoretical expedient work that may be received from energy. Frankly, exergy is not summarized in a single process and could be diminished as a result of irreversibility. In this way, it is possible to separately scrutinize each portion of the cycle and to attain the share of each element in the overall energy loss of the cycle. Concerning gas turbine power plants, with respect to any input fuel or flow into the power plant, the maximum capacity of the power plant can be calculated via exergy analysis. Exergy of matter flow can be categorized into its major constituents comprising kinetic, potential, physical, and chemical exergies. In this paper, kinetic and potential exergies are ignored due to their dispensable rates. Physical exergy is defined as the maximum theoretical useful work acquired whilst a system interacts with an equilibrium state [12]. Chemical exergy is connected with the departure of the chemical composition of a system from its chemical equilibrium. Chemical exergy is an imperative part of exergy in the combustion process [13]. Using the first and second laws of thermodynamics, we have the following exergy balance:

$$
\dot{\mathrm{Ex}} \mathrm{Q}_{\mathrm{Q}}+\sum_{\text {in }} \dot{m}_{i} \mathrm{ex}_{i}=\sum_{\text {out }} \dot{m}_{o} \mathrm{ex}_{o}+\dot{\mathrm{Ex}}_{W}+\dot{\mathrm{Ex}} \mathrm{x}_{D}
$$

where ex is total specific exergy and $\dot{E x}_{D}$ is exergy destruction rate; other terms in this equation are defined as follows [14]:

$$
\begin{aligned}
\dot{\mathrm{Ex}}_{\mathrm{Q}} & =\left(1-\frac{T_{0}}{T_{i}}\right) \dot{Q}_{i}, \\
\dot{\mathrm{Ex}}_{W} & =\dot{W}, \\
\mathrm{ex}_{\mathrm{ph}} & =\left(h-h_{0}\right)-T_{0}\left(s-s_{0}\right), \\
\dot{\mathrm{ex}} & =\dot{\mathrm{ex}}{ }_{\mathrm{ph}}+\dot{\mathrm{ex}} \mathrm{ch}_{\mathrm{ch}}
\end{aligned}
$$

where $T$ is absolute temperature $(\mathrm{K})$ and subscripts $i$ and 0 refer to ambient conditions. The mixture chemical exergy is attained using the following relations [15]:

$$
\mathrm{ex}_{\mathrm{mix}}^{\mathrm{ch}}=\left[\sum_{i=1}^{n} X_{i} \mathrm{ex}^{\mathrm{ch}_{i}}+R T_{0} \sum_{i=1}^{n} X_{i} \ln X_{i}\right] .
$$

The following relation is used to compute fuel exergy [14]:

$$
\xi=\frac{\mathrm{ex}_{f}}{\mathrm{LHV}_{f}} .
$$




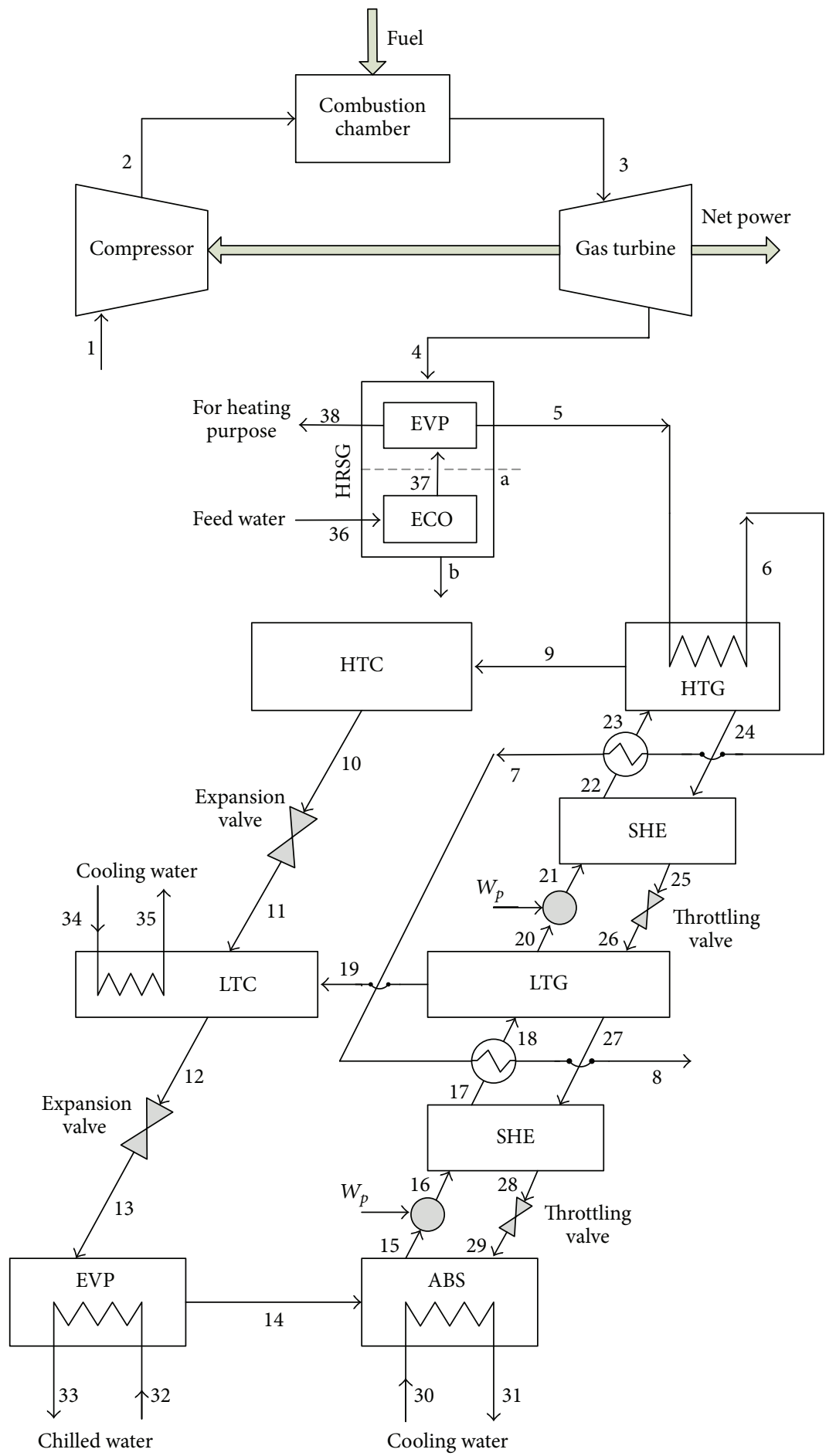

FIGURE 1: Schematic of the CCHP system.

For most regular gaseous fuels, the ratio of chemical exergy to lower heating value is generally close to 1 . While the main fuel used in power plants is methane, we have [14]

$$
\xi_{\mathrm{CH}_{4}}=1.06
$$

\section{Exergoenvironmental Analysis}

Of the advantages of combined heat and power systems, one can name economization in fuel consumption, reducing the contaminators, and, finally, decreasing environmental costs. Fuel saving, which is the consequence of no need 
to another heat generator (such as steam boiler in separate generation), and using the clean fuels such as natural gas are considered the essential factors in decreasing pollution produced by these systems. The environmental benefits of combined power and heat systems use less fuel with higher efficiency, consequently leading to less air pollution. Combustion process in a gas turbine occurs with generating large amount of extra air, since the obtained output power highly depends on the mass flow of the turbine. Gas turbine is among the least pollutant fossil fuel consuming equipment in power generation. The main pollutants of the gas turbines are nitrogen oxides, carbon monoxide, and carbon dioxide. The generated nitrogen oxide (gr per kg of the fuel) from combustion chamber is obtained using the following equation [13]:

$$
\begin{aligned}
m_{\mathrm{NO}_{x}} & =\frac{0.15 \times 10^{16} \tau^{0.5} \exp \left(-71100 / T_{\mathrm{PZ}}\right)}{P_{3}^{0.05}\left(\Delta P_{3} / P_{3}\right)^{0.5}}, \\
m_{\mathrm{CO}} & =\frac{0.179 \times 10^{9} \exp \left(7800 / T_{\mathrm{PZ}}\right)}{P_{3}^{2} \tau\left(\Delta P_{3} / P_{3}\right)^{0.5}} .
\end{aligned}
$$

Here $\tau$ is the residence time in the combustion zone (assumed constant here at $0.002 \mathrm{~s}), T_{\mathrm{PZ}}$ is the primary zone combustion temperature, $P_{3}$ is the combustor inlet pressure, and $\Delta P_{3} / P_{3}$ is the nondimensional pressure drop in the combustion chamber [13]. Using the equation of combustion as well as obtained values for the nitrogen oxides and carbon monoxide, the amount of carbon dioxide emission will be achieved.

\section{Results and Discussion}

Figure 2 presents the charts of energy efficiency, exergy efficiency, and the amount of carbon dioxide emissions per unit of output power for the gas turbine, CHP, and CCHP cycles. It is known that the levels of energy efficiency and exergy efficiency increase with the promotion of gas turbine cycle to CHP and CCHP cycles but the amount of carbon dioxide emissions per unit of output power declines. Increase of CCHP cycle's energy efficiency is much more than its exergy efficiency, because the exergy flow rate of heat transfer is less than the heat rate. In Figure 3, exergy loss is plotted for each of the components of the cycle. According to the chart it is determined that the combustion chamber has the highest rate of irreversibility among other components, and this is due to the chemical reactions taken place in the combustion chamber as well as a large temperature difference between the working fluid and the flame. After combustion chamber, recovery boiler has the most exergy loss.

5.1. Effect of Varying Compressor Pressure Ratio. According to Figure 4, the exergy efficiency for the CCHP cycle is first increased and then decreased. Initially, due to the increased inlet temperature to the combustion chamber and the reduction of the input fuel, efficiency increases. But at a certain pressure ratio, compressor work rate will excess the fuel reduction rate and leads to reduced exergy efficiency. Figure 5 investigates the changes in the amount of carbon dioxide per unit of output power (including electricity, heat,

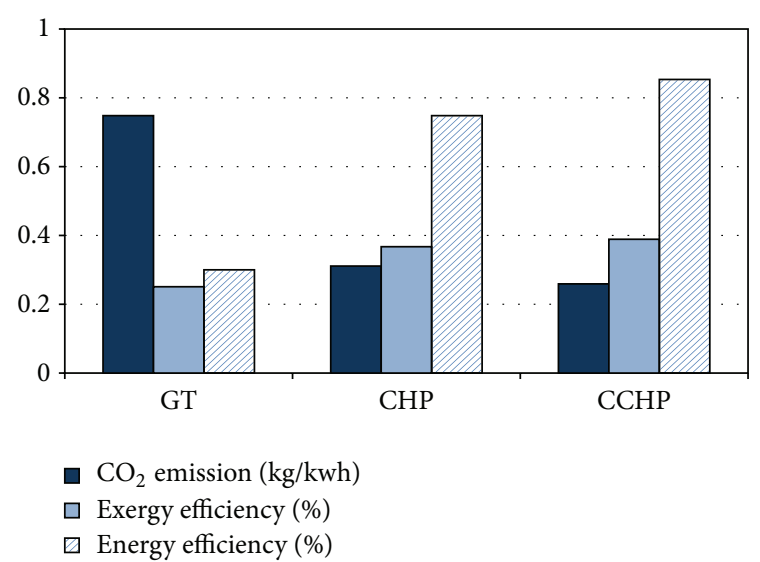

FIGURE 2: Energy efficiency, exergy efficiency, and normalized $\mathrm{CO}_{2}$ emission for CCHP, CHP, and gas turbine cycles.

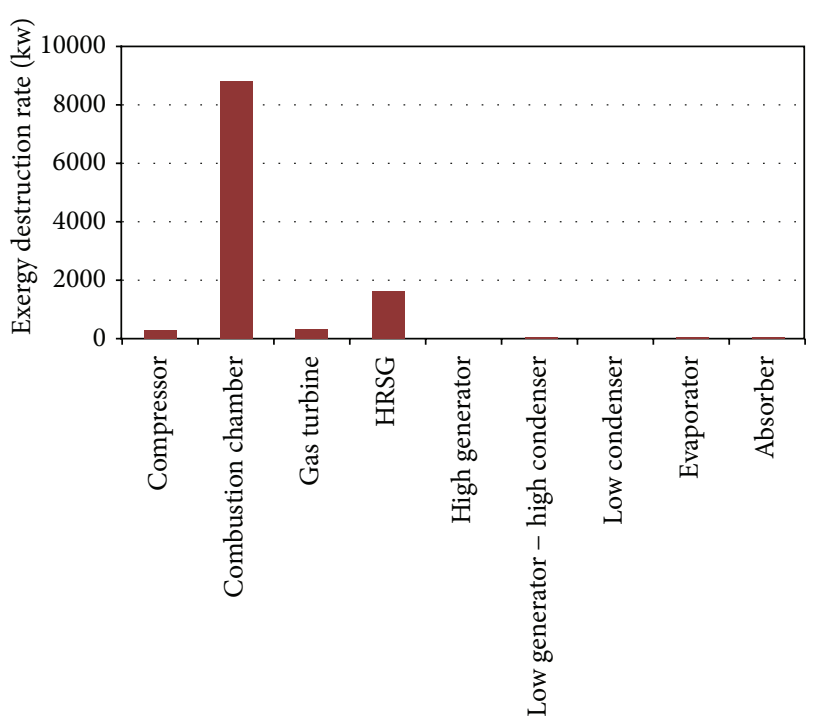

FIGURE 3: Exergy destruction rate for each component of the system.

and cold) compared to the increased compressor pressure. It is observed that, with increasing the pressure ratio of compressor in the desired trigeneration system, the amount of carbon dioxide emissions per unit of output increases, which is due to decrease of heat energy obtained from the recovery boiler.

5.2. Effect of Varying Gas Turbine Inlet Temperature. Gas turbine inlet temperature is one of the most important decision-making parameters in the trigeneration system on the basis of gas turbine. The increase of this temperature can increase the net output of work. Energy balance of the combustion chamber shows that the increase of inlet temperature to the gas turbine will increase the input fuel. As it can be observed in Figure 6, with the increase of inlet temperature to gas turbine, the exergy efficiency of cogeneration cycle will increase. This increase is due to the fact that an increase in the gas turbine inlet temperature will lead to the fact that the rate of network increase in gas 


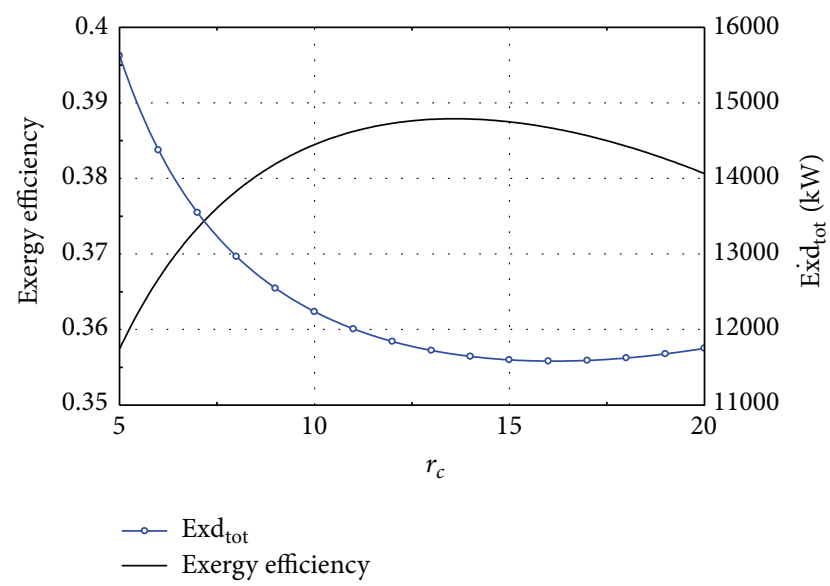

FIGURE 4: Variation with compressor pressure ratio of exergy efficiency and total exergy destruction rate.

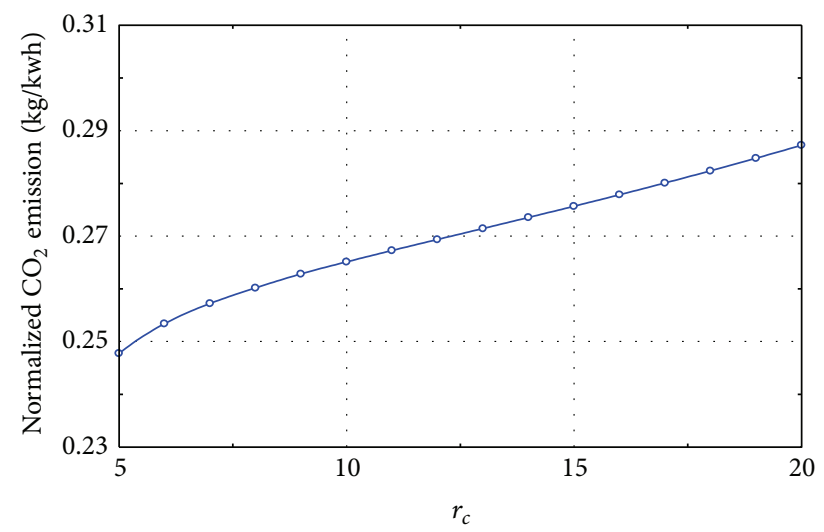

FIGURE 5: Variation with compressor pressure ratio of normalized $\mathrm{CO}_{2}$ emission.

turbine excesses the rate of the increased generated heat in the combustion chamber. This increase is because of the fact that, with increasing gas turbine inlet temperature, the rate of network increase of gas turbine excesses the rate of increase in the amount of heat generated in the combustion chamber. In addition, according to Figure 6, the carbon dioxide emissions per unit of output power are reduced.

5.3. Effect of Varying Gas Turbine Isentropic Efficiency. The isentropic efficiency of the gas turbine is among the important parameters of the design and is indicative of how far the gas turbine performance is from a reversible process. As shown in Figure 7, by increasing the isentropic efficiency of gas turbine, the exergy efficiency of the cycle increases and its exergy loss is reduced.

5.4. Effect of Varying Absorption Generator Temperature. The temperature of the generator in the double-effect absorption chiller is indeed similar to the temperature of the saturated vapor exhausted from the recovery boilers and is related to the recovery boiler pressure. Boiler steam pressure recovery

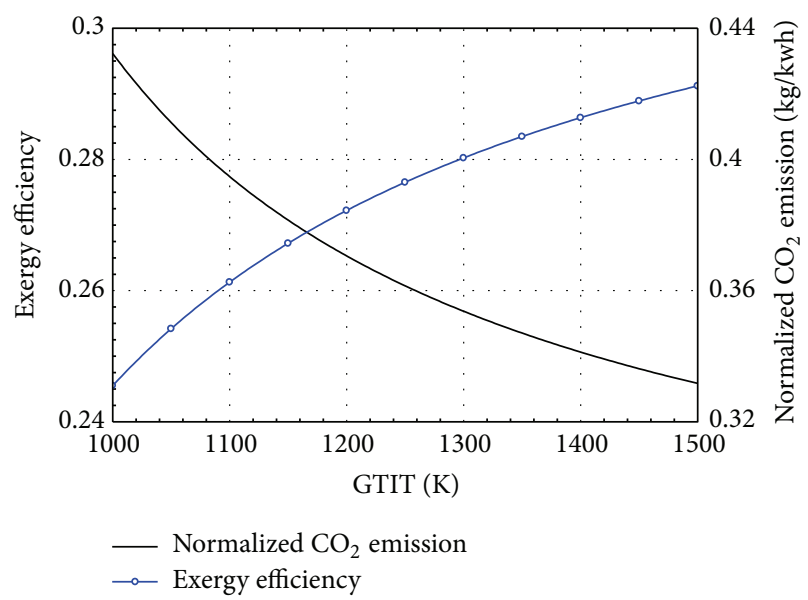

FIGURE 6: Variation with gas turbine inlet temperature of exergy efficiency and normalized $\mathrm{CO}_{2}$ emission.

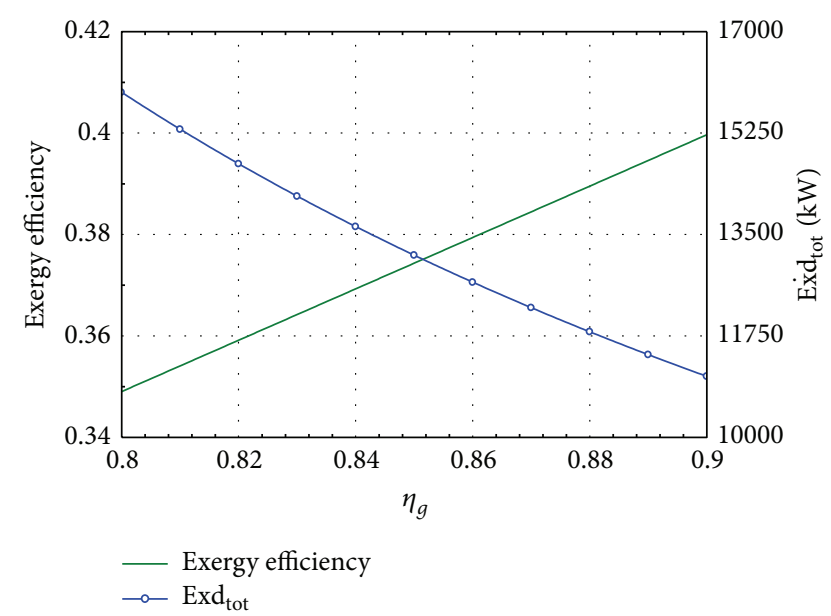

FIGURE 7: Variation with gas turbine isentropic efficiency of exergy efficiency and total exergy destruction rate.

is one of the important design parameters. By increasing the temperature of the exhausting saturated vapors from the recovery boilers, the amount of heat from the recovery boiler is reduced. And the cooling rate of absorption chiller increases. But the rate increase of absorption chiller cooling is much smaller than the rate of heat recovery boiler. Thus, as it can be seen in Figure 8, the exergy efficiency increases with increase of saturated steam temperature, because the exergy related to heat obtained from the recovery boiler and the exergy of cooling in the absorption chiller increase due to increase of saturated steam temperature. The coefficient of performance (COP) for the absorption chiller is achieved through dividing the cooling obtained from evaporator by the heat consumed in the generator. Hence, by increasing the absorption chiller generator temperature, the amount of heat used in the generator reduces and the cooling produced from the chiller evaporator increases; as shown in Figure 9, the performance ratio of chiller improves. 


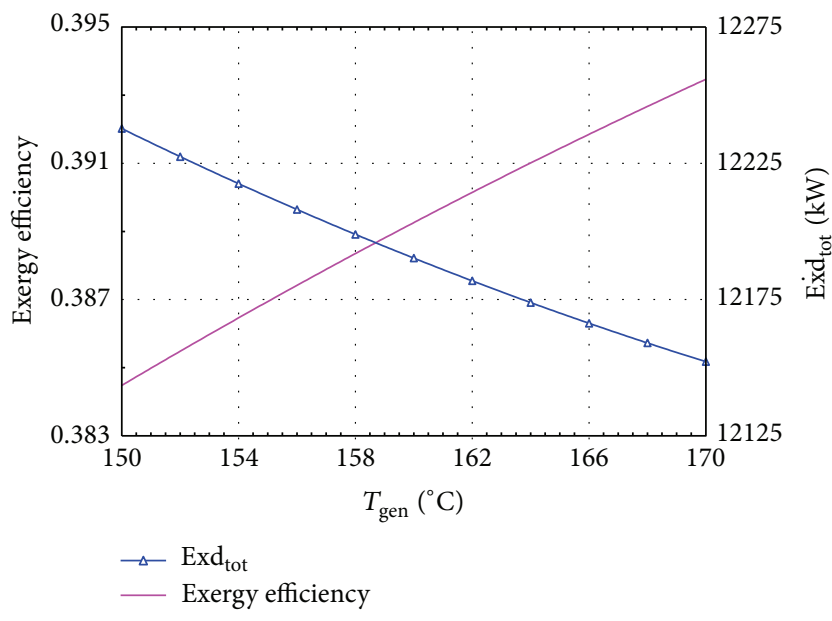

FIGURE 8: Variation with absorption generator temperature of exergy efficiency and total exergy destruction rate.

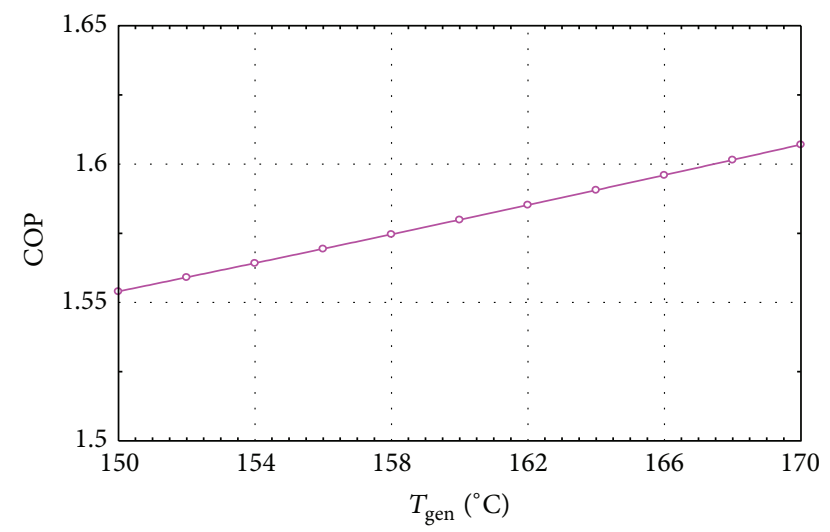

FIGURE 9: Variation with absorption generator temperature of absorption chiller COP.

\section{Conclusions}

A comprehensive thermodynamic modeling was carried out for a trigeneration system based on a double-effect absorption chiller. This study shed light on the importance of integrated energy system in order to achieve higher exergy efficiency and lower emission compared to single generation energy systems. Exergy analysis showed that the combustion chamber and the heat recovery boiler have the most exergy destruction compared to other components. This is mainly due to the large temperature difference for the heat transfer in both listed components and the combustion reaction in the combustion chamber. System performance significantly is affected by changes in pressure ratio compressor, inlet temperature to gas turbine, and isentropic efficiency of the high-temperature generator. According to the figures obtained from the previous section, the following conclusions can be listed:

(i) Exergy efficiency of the CCHP cycle is more than $\mathrm{CHP}$ and gas turbines cycles. (ii) Exergy loss in the absorption chiller is less than other CCHP components.

(iii) With the increase in compressor pressure ratio, exergy efficiency for the entire CCHP cycle is first increased and then decreased and emissions of carbon dioxide increase as well.

(iv) Exergy efficiency of the CCHP cycle increases with the increase of gas turbine isentropic efficiency.

(v) CCHP cycle produces less carbon dioxide per unit output power compared to CHP and gas turbine cycles.

(vi) Exergy efficiency of the CCHP, CHP, and gas turbine cycles increases with the increasing of the gas turbine inlet temperature.

(vii) Exergy loss of the CCHP cycle decreases with increasing the high-temperature absorption chiller temperature, but its exergy efficiency increases in this process.

\section{Nomenclature}

Cp: $\quad$ Specific heat at constant pressure $(\mathrm{kJ} / \mathrm{kg} \mathrm{K})$

ex: $\quad$ Specific exergy flow $(\mathrm{kJ} / \mathrm{kg})$

Ex: $\quad$ Exergy flow rate $(\mathrm{kW})$

$\mathrm{Ex}_{D}: \quad$ Exergy destruction rate $(\mathrm{kW})$

$h: \quad$ Specific enthalpy $(\mathrm{kJ} / \mathrm{kg})$

LHV: Lower heating value $(\mathrm{kJ} / \mathrm{kg})$

$\dot{m}: \quad$ Mass flow rate $(\mathrm{kg} / \mathrm{s})$

$P: \quad$ Pressure (bar)

$\Delta P: \quad$ Pressure drop (bar)

Q: $\quad$ Heat rate $(\mathrm{kW})$

R: $\quad$ Gas constant $(\mathrm{kJ} / \mathrm{kg} \mathrm{K})$

$s: \quad$ Specific entropy $(\mathrm{kJ} / \mathrm{kg} \mathrm{K})$

$T: \quad$ Temperature (K)

$\dot{W}: \quad$ Work rate $(\mathrm{kW})$

AP: Approach point

CHP: Combined heat and power

HTC: High temperature condenser

HTG: High temperature generator

SHE: Solution heat exchanger

LTC: Low temperature condenser

LTG: Low temperature generator

ABS: Absorber

ECO: Economizer

EVP: Evaporator

HRSG: Heat recovery steam generator

PP: Pinch point.

\section{Greek Symbols}

$\gamma$ : Specific heat ratio.

Subscripts

C: Compressor

CC: Combustion chamber

D: Destruction 


\author{
ex: Exergy \\ $f:$ Fuel \\ $g$ : Combustion gases \\ GT: Gas turbine \\ $i$ : Inlet condition.
}

\section{Superscript}

ch: Chemical rate.

\section{Competing Interests}

The author declares that there are no competing interests.

\section{References}

[1] F. A. Al-Sulaiman, I. Dincer, and F. Hamdullahpur, "Exergy analysis of an integrated solid oxide fuel cell and organic Rankine cycle for cooling, heating and power production," Journal of Power Sources, vol. 195, no. 8, pp. 2346-2354, 2010.

[2] V. Havelský, "Energetic efficiency of cogeneration systems for combined heat, cold and power production," International Journal of Refrigeration, vol. 22, no. 6, pp. 479-485, 1999.

[3] V. Athanasovici, O. Le Corre, G. Brecq, and M. Tazerout, "Thermoeconomic analysis method for cogeneration plants," in Proceedings of ECOS Netherlands, pp. 157-164, 2000.

[4] E. Minciuc, O. Le Corre, V. Athanasovici, M. Tazerout, and I. Bitir, "Thermodynamic analysis of tri-generation with absorption chilling machine," Applied Thermal Engineering, vol. 23, no. 11, pp. 1391-1405, 2003.

[5] P. K. Sahoo, "Exergoeconomic analysis and optimization of a cogeneration system using evolutionary programming," Applied Thermal Engineering, vol. 28, no. 13, pp. 1580-1588, 2008.

[6] A. Huicochea, W. Rivera, G. Gutiérrez-Urueta, J. C. Bruno, and A. Coronas, "Thermodynamic analysis of a trigeneration system consisting of a micro gas turbine and a double effect absorption chiller," Applied Thermal Engineering, vol. 31, no. 16, pp. 33473353, 2011.

[7] P. Ahmadi, M. A. Rosen, and I. Dincer, "Greenhouse gas emission and exergo-environmental analyses of a trigeneration energy system," International Journal of Greenhouse Gas Control, vol. 5, no. 6, pp. 1540-1549, 2011.

[8] F. A. Al-Sulaiman, I. Dincer, and F. Hamdullahpur, "Energy analysis of a trigeneration plant based on solid oxide fuel cell and organic Rankine cycle," International Journal of Hydrogen Energy, vol. 35, no. 10, pp. 5104-5113, 2010.

[9] Z. Amrollahi, I. S. Ertesvåg, and O. Bolland, “Thermodynamic analysis on post-combustion $\mathrm{CO}_{2}$ capture of natural-gas-fired power plant," International Journal of Greenhouse Gas Control, vol. 5, no. 3, pp. 422-426, 2011.

[10] B. Rezaie and M. A. Rosen, "District heating and cooling: review of technology and potential enhancements," Applied Energy, vol. 93, pp. 2-10, 2012.

[11] H. Kurt, Z. Recebli, and E. Gedik, "Performance analysis of open cycle gas turbines," International Journal of Energy Research, vol. 33, no. 3, pp. 285-294, 2009.

[12] I. Dincer and M. A. Rosen, "Energy, environment and sustainable development," Applied Energy, vol. 64, no. 1-4, pp. 427-440, 1999.
[13] P. Ahmadi and I. Dincer, "Exergoenvironmental analysis and optimization of a cogeneration plant system using Multimodal Genetic Algorithm (MGA)," Energy, vol. 35, no. 12, pp. 51615172, 2010.

[14] A. Mousafarash and P. Ahmadi, "Exergy and exergo-economic based analysis of a gas turbine power generation system," in Progress in Exergy, Energy and the Environment, chapter 7, Springer, 2014.

[15] A. Bejan, G. Tsatsaronis, and M. Moran, Thermal Design and Optimization, John Wiley \& Sons, New York, NY, USA, 1996. 


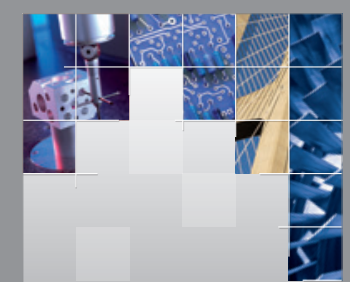

\section{Enfincering}
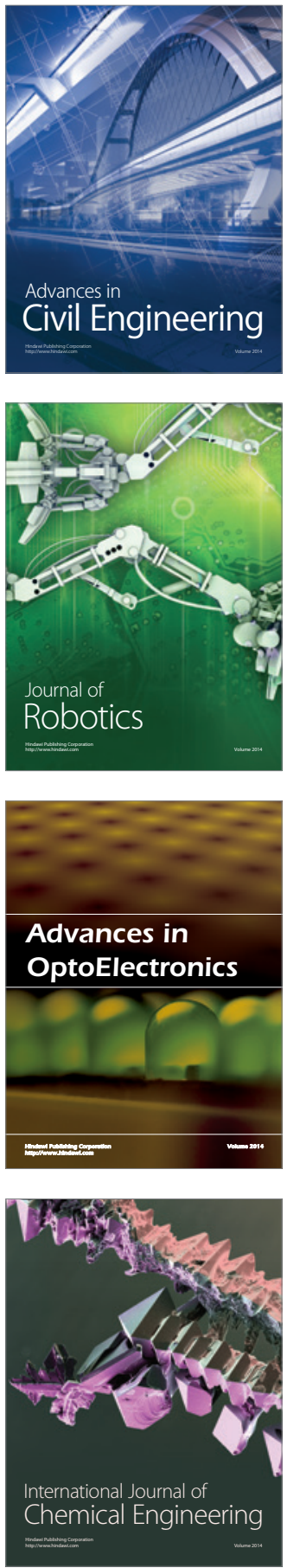

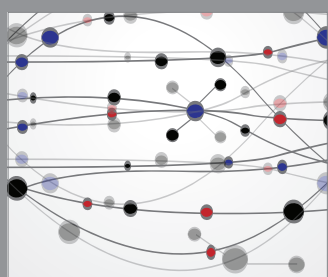

The Scientific World Journal

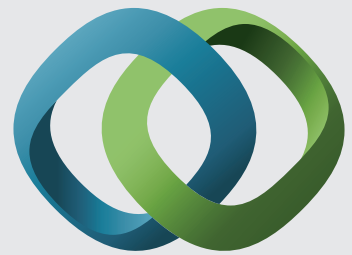

\section{Hindawi}

Submit your manuscripts at

http://www.hindawi.com
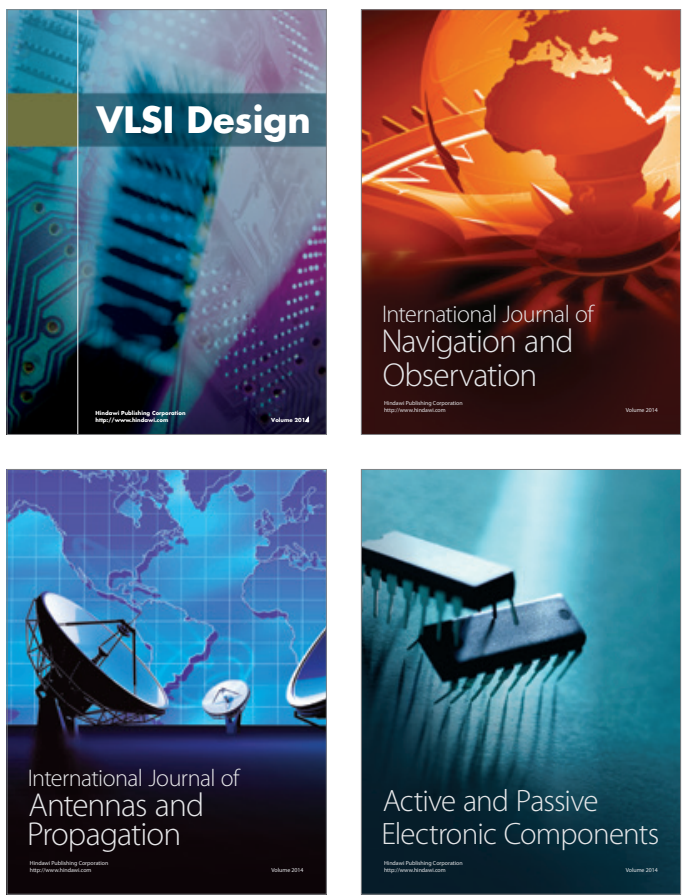
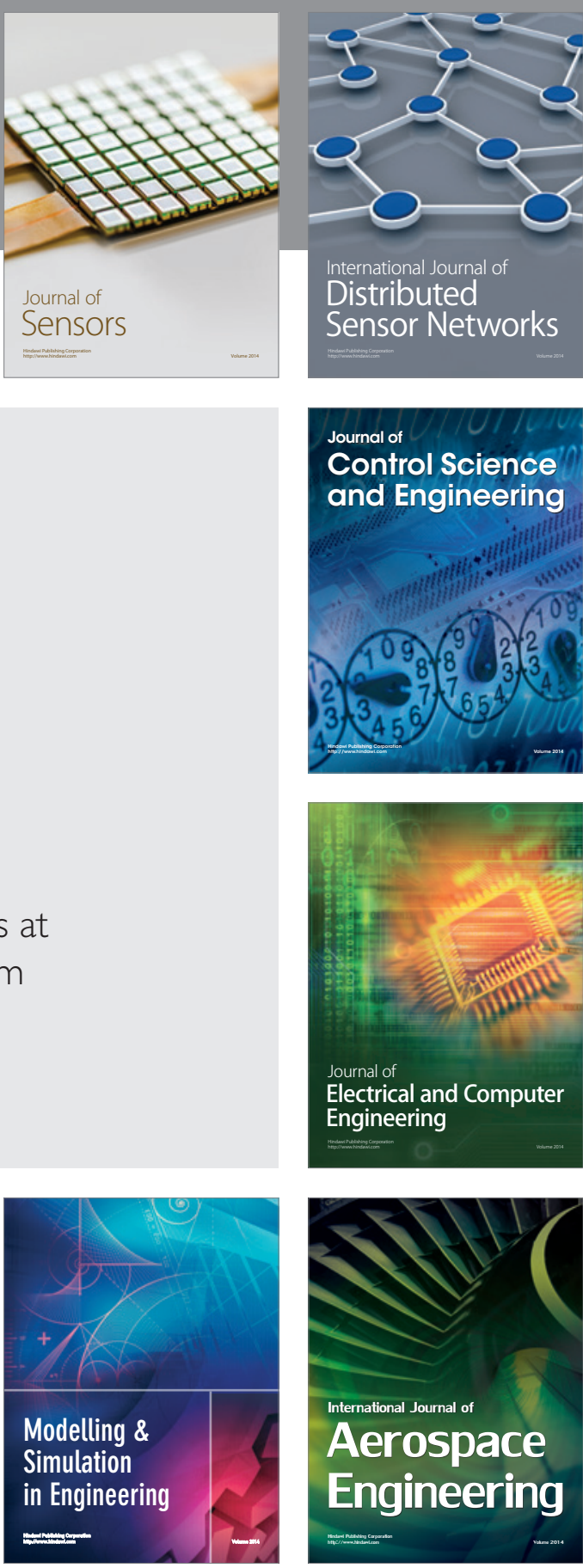

International Journal of

Distributed

Sensor Networks

Journal of

Control Science

and Engineering
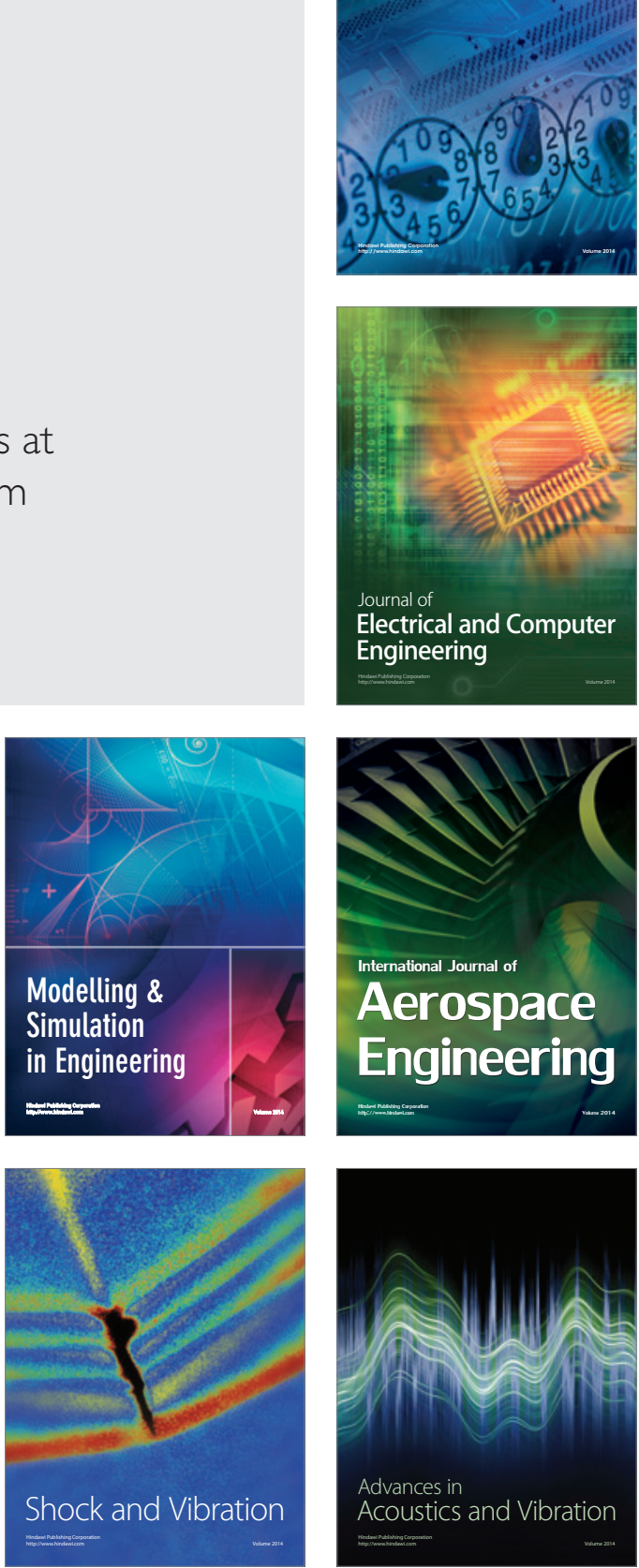